\title{
Quality of Care in Long-Term Hemodialysis Patients in Mexico
}

Torres-Díaz J A ${ }^{1}$, Gonzalez-Gonzalez J G G,5, ZúnigaHernández J A ${ }^{5}$, Olivo-Gutiérrez MC 1,2,3, GarzaGarcía CA ${ }^{12,3}$, Sánchez-Romo SM1, VillarrealMartínez J Z ${ }^{2}$ and Rodríguez-Gutiérrez $\mathbf{R}^{4,5,6 *}$ ${ }^{1}$ Internal Medicine Department. Hospital Universitario Dr. J osé Eleuterio González, Universidad Autónoma de Nuevo León. Monterrey, Nuevo León, México

${ }^{2}$ Nephrology Division. Hospital Universitario Dr. J osé Eleuterio González, Universidad Autónoma de Nuevo León. Monterrey, Nuevo León, México

${ }^{3}$ Centro Regional de Enfermedades Renales (CRER). Hospital Universitario Dr. J osé Eleuterio González, Universidad Autónoma de Nuevo León. Monterrey, Nuevo León, México

${ }^{4}$ Endocrinology Division. Hospital Universitario Dr. J osé Eleuterio González, Universidad Autónoma de Nuevo León. Monterrey, Nuevo León, México

${ }^{5}$ Plataforma INVEST-KER Unit Mayo Clinic (KER Unit Mexico), School of Medicine, Universidad Autonoma de Nuevo Leon, Monterrey, Mexico

${ }^{6}$ Knowledge and Evaluation Research Unit in

Endocrinology, Mayo Clinic, Rochester, Minnesota, USA

*Corresponding author: Rodriguez-Gutierrez R, Endocrinology Division, Hospital Universitario, Universidad Autónoma de Nuevo León. Monterrey, Nuevo León, México. Av. Francisco I. Madero, Col. Mitras Centro. Monterrey, N.L. México

Received: May 06, 2021; Accepted: J une 09, 2021;

Published: J une 16, 2021

\section{Introduction}

The number of patients with end stage renal disease (ESRD) requiring dialysis is increasing worldwide [1]. From 2000 to 2015, the incidence increased 32\%, from 343 per million in 2000 to 453 per million in 2015 [2]. The morbidity and mortality rates of this population are very high particularly in the first year after initiation of renal replacement therapy in which it can exceed 25\% [3]. Therefore, it is important to identify risk factors in which we can intervene in order to reduce mortality rates [4]. Some of these factors have been identified by the National Kidney Foundation after developing a series of evidence-based guidelines for the care of patients with kidney disease, the Kidney Disease Outcomes Quality Initiative (KDOQI). The KDOQI guidelines recommend timely nephrology referral, nutritional consultation, fistula placement for dialysis access, control of anemia, acidosis, and mineral and bone metabolism parameters [5]. Several studies suggest that there is a significant correlation between the number of KDOQI guidelines with survival and quality of life [6-8], at least in the first year after the initiation of renal replacement therapy [9]. However, only $1.6 \%$ of patients with ESRD on hemodialysis achieve 3 goals $[1,10]$. Also, evidence suggests that a well-established program of hemodialysis improved the blood pressure control, anemia management, serum albumin levels and quality of life [11-13].

In Mexico, the ESRD is one of the main causes of hospitalization and represents a concerning public health problem [14]. ESRD is reported among the 10 leading causes of death, with an annual mortality rate of 12 deaths per 100,000 [15]. In our country, the use of peritoneal dialysis has historically predominated, although hemodialysis has been recently promoted. However, human resources and infrastructure availability along with social and economic factors, as well as the limited number of understaffed and centralized dialysis facilities contribute to the inadequate practice of nephrology in Mexico [16] At the same time approximately 54\% of the population does not have access to health social security and cannot afford to pay for renal replacement therapy out of pocket additionally restricting clinical care for them [15]. There is no precise information about hemodialysis centers in our country, as there is no centralized national registry of cases of kidney disease to determine the real incidence and prevalence, cost analysis, action planning, as well as criteria for success and quality in treatment [17]. In a study that assessed the quality of hemodialysis units in Mexico, it was found that there is an unacceptably high number of units with poor quality and that the mortality rate was correlated with the quality of the units [18].
Austin J Nephrol Hypertens - Volume 8 Issue 1 - 2021 ISSN : 2381-8964 | www.austinpublishing group.com Rodríguez-Gutiérrez et al. @ All rights are reserved
Citation: Torres-Díaz JA, Gonzalez-Gonzalez JG, Zúniga-Hernández JA, Olivo-Gutiérrez MC, Garza-García CA, Sánchez-Romo SM, et al. Quality of Care in Long-Term Hemodialysis Patients in Mexico. Austin J Nephrol Hypertens. 2021; 8(1): 1091. 
The increasing number of hemodialysis patients may potentially compromise the ability of clinicians to provide optimal care. Although management of hemodialysis patients is complex and multifactorial, many of the individual components of care are amenable to protocolization [19]. Although no studies indicate that such protocols improve clinical outcomes, they appear to improve process of care in patients with or without ESRD [20].

Consequently we decided to perform this cross-sectional study with the objective to determine if patients with ESRD in renal replacement therapy with hemodialysis achieved the KDOQI goals, particularly the objectives related to the management of anemia, serum albumin level, use of arterio-venous fistula and adequacy of dialysis through the dialysis dose $(\mathrm{Kt} / \mathrm{V})$ and its association with patients' outcomes [21,22].

\section{Methods}

\section{Study design and data collection}

After approval of the study from the ethics committee of our University we consecutively and randomly included patients with ESRD at the Regional Center for Kidney Diseases (CRER) of the "Hospital Universitario Dr. José Eleuterio González", in Monterrey, Nuevo León between January 01 to December 31, 2019. Included participants had a minimum of three months of enrollment in the CRER program, over 18 years of age, and absence of health social security or health insurance. Patients who underwent kidney transplant, changed dialysis modality, or refused to participate were excluded from the analysis.

This study used data from the database system of the Regional Center for Kidney Diseases, a local data system that collects information of the dialysis patients enrolled in the program. The information extracted included age, gender, main cause of Chronic Kidney Disease (CKD), occupation status, and comorbidities (congestive heart failure, ischemic heart disease, cerebrovascular disease, hypertension, diabetes mellitus and current use of insulin, chronic obstructive pulmonary disease, tobacco use, malignant neoplasm, HIV-positive status, systematic lupus erythematosus). Every month, dialysis facility staff extracted patient data, including patient's weight before and after dialysis, dialysis session length, first documented blood urea nitrogen concentration before and after dialysis, type of vascular access, hemoglobin value, and serum albumin value.

The following indicators were analyzed and were considered for positive if: hemoglobin level of $\geq 11 \mathrm{~g} / \mathrm{dl}$, blood pressure $<140 / 90$ $\mathrm{mmHg}$, serum albumin $\geq 4 \mathrm{~g} / \mathrm{dl}$ and use of arteriovenous fistula. The blood pressure figures evaluated corresponded to those recorded in the clinical file prior to the start of the scheduled hemodialysis session. The hemoglobin and serum albumin values analyzed were taken from the studies carried out as part of the monthly follow-up of each patient at the hemodialysis center.

\section{Statistical analysis}

Descriptive statistics were used to characterize the study population. Proportions were used for categorical variables and mean and standard deviation for continuous variables. Descriptive statistics were also used to assess the proportion of patients who met the criteria. The association between mortality and the fulfillment of the KDOQI goals was evaluated with a logistic regression model, mortality being a dependent variable and the achievement of the goals the covariate of the model. A linear regression model was also performed with the number of readmissions as the dependent variable and the same covariates of the logistic regression model. Statistical analyses were conducted by using SPSS, version 10.0 (SPSS, Inc., Chicago, Illinois).

\section{Results}

\section{Baseline characteristics}

Of the 124 patients enrolled in the CRER hemodialysis program, sixty-four $(51 \%)$ of them were men with an average age of $50 \pm 15$ years, 68 (55\%) had diabetes mellitus, 107 (86\%) had hypertension primary school and $99(80 \%)$ remained economically inactive. The mean number of hemodialysis sessions per week was $2.23 \pm 0.55$. The average duration of patients in the hemodialysis program was 37 months, with an adherence rate of $90 \%$. Table 1 shows the characteristics of the population.

\section{Achievement of KDOQI guidelines goals}

A total of 120 patients met the eligibility criteria to be included in the sample for analysis. For the 4 clinical measurement targets we examined, the hemoglobin and blood pressure values of all patients were reported; for $76(63.3 \%)$ a serum albumin value was reported; and $115(95.8 \%)$ had a report on the type of vascular access. The mean hemoglobin in the population was $9.1 \mathrm{~g} / \mathrm{dl} \pm 2.3$ and only 24 (19.4\%) of the patients had a hemoglobin greater than $11 \mathrm{~g} / \mathrm{dl}, 18$ of the patients (14.6\%) met the albumin goal, with a mean albumin of $3.2 \mathrm{~g} /$ $\mathrm{dl}$, the mean systolic blood pressure was $143 \pm 27 \mathrm{mmHg}, 69$ (55.6\%) met this goal and only $9(7.3 \%)$ of the patients have an arterio-venous fistula as an access route for hemodialysis, while 106 (92.7\%) have a chronic catheter (Table 2). There was a mortality of 14 patients that represents $11.2 \%$ during the observation period.

Patients were categorized by the number of measured goals

Table 1: Baseline patient characteristics.

\begin{tabular}{|c|c|c|}
\hline Parameter & & Mean \pm SD \\
\hline \multicolumn{3}{|c|}{$n=124$} \\
\hline Sex & Female (n [\%]) & $60(48.4)$ \\
\hline Age (years) & & $50.03 \pm 15.15$ \\
\hline BMI $\left(\mathrm{kg} / \mathrm{m}^{2}\right)$ & & $27.3 \pm 6$ \\
\hline Diabetes Mellitus (n [\%]) & & $67(54)$ \\
\hline Hypertension (n [\%]) & & $107(86)$ \\
\hline Economically active ( $\mathrm{n}[\%]$ ) & & $24(19)$ \\
\hline \multirow[t]{3}{*}{ Predialysis } & Weight (kg) & $71.9 \pm 18.6$ \\
\hline & $\begin{array}{l}\text { Systolic blood pressure } \\
(\mathrm{mmHg})\end{array}$ & $143 \pm 27$ \\
\hline & $\begin{array}{l}\text { Diastolic blood pressure } \\
(\mathrm{mmHg})\end{array}$ & $78 \pm 16$ \\
\hline Postdialysis & Weight (kg) & $69.4 \pm 18$ \\
\hline Antihypertensive drugs & & $1.66 \pm 1.08$ \\
\hline $\begin{array}{l}\text { Hemodialysis sesions per } \\
\text { week }\end{array}$ & & $2.23 \pm 0.55$ \\
\hline Hemodialysis duration (min) & & $210 \pm 28.5$ \\
\hline Albumin (g/dl) & & $3.23 \pm 0.88$ \\
\hline Hemoglobin (g/dl) & & $9.1 \pm 2.32$ \\
\hline
\end{tabular}

SD: Standard deviation 
Table 2: Percentage of clinical performance measures met.

\begin{tabular}{|l|c|}
\hline \multicolumn{1}{|c|}{ Performance mesures } & n (\%) \\
\hline$n=124$ & \\
\hline Hemoglobin at goal $^{\mathrm{a}}$ & $24(19.4)$ \\
\hline Albumin at goal $^{\mathrm{b}}$ & $18(14.6)$ \\
\hline BP at goal & $\mathrm{c}$ \\
\hline A/V fistula & $69(55.6)$ \\
\hline
\end{tabular}

KDOQI, Kidney Disease Outcomes Quality Iniciative; A/V, arteriovenous fistula aHemoglobin $\geq 11 \mathrm{~g} / \mathrm{dl}$.

${ }^{\mathrm{b}}$ Albumin $\geq 4 \mathrm{~g} / \mathrm{dl}$.

'BP $<140 / 90$

Table 3: Number of KDOQI goals met.

\begin{tabular}{|c|c|}
\hline Guideline Goals & $\mathbf{n}(\%)$ \\
\hline $\mathrm{n}=124$ & \\
\hline $\mathrm{a} 0$ & $14(11.3)$ \\
\hline 1 & $51(41.1)$ \\
\hline 2 & $43(34.7)$ \\
\hline 3 & $11(8.9)$ \\
\hline 4 & $5(4.0)$ \\
\hline
\end{tabular}

KDOQI, Kidney Disease Outcomes Quality Initiative

Table 4: Odds ratio for mortality by KDOQI performance measure.

\begin{tabular}{|c|c|c|}
\hline Performance mesures & OR & $95 \% \mathrm{Cl}$ \\
\hline Number of KDOQI goals met & 1.1 & $(0.5-2.8)$ \\
\hline Hemoglobin at goal ${ }^{a}$ & 0.3 & $(0.03-3.2)$ \\
\hline Albumin at goal ${ }^{b}$ & 0.7 & $(0.4-1.4)$ \\
\hline $\mathrm{BP}$ at goal ${ }^{\mathrm{c}}$ & 0.7 & $(0.2-2.7)$ \\
\hline A/V fistula & 2.1 & $(0.3-16.9)$ \\
\hline
\end{tabular}

KDOQI, Kidney Disease Outcomes Quality Initiative; OR, Odds ratio; A/V arteriovenous fistula;

aHemoglobin $\geq 11 \mathrm{~g} / \mathrm{dl}$

${ }^{\mathrm{b} A l b u m i n} \geq 4 \mathrm{~g} / \mathrm{dl}$.

cBP $<140 / 90$

achieved during the follow-up period. Fourteen (11.3\%) of the analyzed patients did not meet any of the analyzed goals, $51(41.1 \%)$ met a clinical goal, $43(34.7 \%)$ met two goals, 11 (8.9\%) met 3 of the analyzed criteria and only 5 patients (4\%) met the four clinical objectives. Table 3 shows the number of KDOQI guidelines met.

The results of the logistic regression model to determine the association between the achievement of the goals and the mortality criteria are found in Table 4. The number of goals met had an OR for mortality of 1.1 (95\% CI 0.5-2.8), hemoglobin at goal OR 0.3 (CI 95\% 0.03-3.2), albumin at goal OR 0.7 (CI 95 0.4-1.4\%) and target systolic blood pressure an OR 0.7 (95\% CI 0.2-2.7). Of these, none showed an association with the increase in mortality.

The results of the linear regression model to determine the association between the achievement of goals and the number of hospital admissions are shown in Table 5. The beta correlation with the number of KDOQI goals met was 0.246 (95\% CI -0.872-1.365), with hemoglobin at goals of -1.55 (95\% CI -3.75-0.642), with albumin in goals of -0.26 (CI 95\% -1.075-0.55), with BP in goals of -0.73 (CI 95\% -2.5-1.04) and presence of A/V fistula -1.1 (CI 95\% -4.3-2.01). Of these, none showed an association with the increase in the number of hospital readmissions.
Table 5: Association of the hospital admissions and KDOQI performance measure met.

\begin{tabular}{|l|c|c|}
\hline \multicolumn{1}{|c|}{ Performance mesures } & Beta & $95 \%$ Cl \\
\hline Number of KDOQI goals met & 0.246 & $(-0.872-1.365)$ \\
\hline Hemoglobin at goal $^{\mathrm{a}}$ & -1.55 & $(-3.75-0.642)$ \\
\hline Albumin at goal $^{\mathrm{b}}$ & -0.26 & $(-1.075-0.55)$ \\
\hline BP at goal & -0.73 & $(-2.5-1.04)$ \\
\hline A/V fistula & -1.1 & $(-4.3-2.01)$ \\
\hline
\end{tabular}

KDOQI, Kidney Disease Outcomes Quality Initiative; OR, Odds ratio; A/V arteriovenous fistula;

aHemoglobin $11 \mathrm{~g} / \mathrm{dl}$.

${ }^{\mathrm{b}}$ Albumin $\geq 4 \mathrm{~g} / \mathrm{dl}$.

${ }^{\mathrm{C}} \mathrm{BP}<140 / 90$

\section{Conclusion}

To our knowledge, this is the first study to evaluate adherence and compliance with the recommendations established by the KDOQI for the management of patients with end-stage chronic kidney disease in replacement therapy with hemodialysis and to evaluate the association between compliance and mortality in a Mexican population. This study shows that the attainment of the performance measures is low, however, similar to that reported worldwide, likewise, a mortality rate similar to that reported in the literature. We did not find a statistically significant association between the fulfillment of a cumulative number of KDOQI performance measures and the outcomes of patients with ESRD in our sample of patients.

In our cohort, we demonstrate that a tenth of the participants did not meet any of the analyzed goals, about half met a clinical goal, a third met two goals, a tenth met three of the analyzed criteria, and one in 25 patients met all four objectives. In our cohort, one in eighteen had an arteriovenous fistula, more than half had target blood pressure, a fifth had hemoglobin greater than $11 \mathrm{~g} / \mathrm{dl}$, and one in nine had albumin greater than $4 \mathrm{~g} / \mathrm{dl}$. Of the criteria analyzed, blood pressure was the goal most met, with the average use of 2 antihypertensive drugs.

This study shows that although mortality and the number of hospital readmissions were not affected by the low percentage of clinical goals attained, there is a great field of opportunity in the care of patients with chronic kidney disease.

Since the inception of the Regional Center for Kidney Diseases in 2018, the adoption and use of the international clinical practice guidelines in the care of such patients has been an important mission and the findings from this report are used to target facility-specific quality improvement interventions and to monitor trends in the quality of care. The low rates of guidelines met is probably due to multiple factors, inside and outside the dialysis unit. However, our center did not experience a higher rates of mortality, as expected, that those reported nationally [14] and internationally [1].

The low frequency of patients meeting KDOQI guidelines goals is similar to the reports that exist from other centers in the world, these reports also show a significant correlation with the accomplishment of the guidelines and the rate of mortality $[6,9,10]$. Recent studies in low-income countries reveal the low accomplishment of the guidelines goals in different hemodialysis centers which was attributed to socioeconomic factors, this low accomplishment was 
associated with the poor outcomes in patients with ESRD [10,23]. However, it is noteworthy that in our group of patients there was no direct association as suggested by these studies. These findings should be interpreted with caution. Our findings may be related to diverse factors, some of them, the small number of patients included in our cohort, the low mortality rate shown in the analysis period or the presence of multiple variables not analyzed as clinical performance measures.

The high prevalence of patients who do not meet these goals is worrisome and an important topic of discussion not only in our country. This represents an area of opportunity to establish improvements in the management of these patients. This study should be an attempt to initiate a national registry of dialysis patients in order to generalize the adoption of international guidelines that will improve the morbidity and mortality rates, and to establish a core outcome set to be consistently measured and reported in the hemodialysis centers that will improve the integrity, transparency, implementation and contribution to research to patients requiring hemodialysis.

Further research is needed, focusing on defining barriers to adequate care, developing interventions to improve the quality of care, and making the necessary adaptations of the guidelines to our population. Undoubtedly, there are multiple factors that intervene in this problem and studies that define the main barriers that exist in our country are required. The barriers that we consider to be important factors are socioeconomic and include the low adherence of patients to medical treatment, high costs of replacement therapy, the shortage of hemodialysis centers and the time to be invested. In addition, comorbid medical conditions may make it more difficult to achieve intermediate outcomes for dialysis dose, anemia, and dialysis access. All countries, are facing the problem of diminishing financial resources to deal with the increasing health care costs brought on by this life-saving modality of RRT [24]. In a cost-effective analysis in a Saudi center, the mean total cost of each maintenance HD session was estimated to be 297 USD and a mean total annual cost of dialysis per patient was estimated to be more than 40,000 USD that is well below the average cost in the industrialized countries although a high standard of care is maintained [24-26].

The strength of this study relies in the novelty to answer a question that has not been addressed in a Mexican population. At the same time, this study has participants that are representative of a high proportion of patients that do not have social security or health insurance. The low loss of patients in the cohort and the availability of the most data of our patients is also one of the strengths. However, this is a single center report in the northeastern Mexico, and the generalizability to other regions of the country could not be done. Other limitations are those inherent in observational studies in which the causality cannot be inferred. Because this was not a randomized, controlled clinical trial but a retrospective analysis of a limited set of variables, it is not possible to determine causality, only associations of these variables with the outcomes examined. Our data were limited by a single measurement of laboratory values used to define guidelines goals achievement. The missing data were not included in the analysis.

In conclusion, the attainment of clinical goals and the mortality rate in our center is similar to that reported in the world literature. Our study did not find a significant association between compliance with clinical guidelines and mortality or the number of hospital admissions in CKD patients on hemodialysis. It is necessary to find a method to improve the adequacy of dialysis and the quality of life of these patients.

\section{Acknowledgment}

To the CRER personnel.

\section{References}

1. Slinin $Y$, Guo H, Gilbertson DT, et al. Meeting KDOQI Guideline Goals at Hemodialysis Initiation and Survival during the First Year. Clin J Am Soc Nephrol. 2010; 5: 1574-1581.

2. Gilbertson DT, Liu J, Xue JL, et al. Projecting the Number of Patients with End-Stage Renal Disease in the United States to the Year 2015. J Am Soc Nephrol. 2005; 16: 3736-3741.

3. Collins AJ, Foley RN, Gilbertson DT, Chen S-C. United States Renal Data System public health surveillance of chronic kidney disease and end-stage renal disease. Kidney Int Suppl. 2015; 5: 2-7.

4. Plantinga LC, Fink NE, Jaar BG, et al. Attainment of clinical performance targets and improvement in clinical outcomes and resource use in hemodialysis care: a prospective cohort study. BMC Health Serv Res. 2007; 7: 5 .

5. Daugirdas JT, Depner TA, Inrig J, et al. KDOQI Clinical Practice Guideline for Hemodialysis Adequacy: 2015 Update. Am J Kidney Dis. 2015; 66: 884-930.

6. Collins AJ. Influence of target hemoglobin in dialysis patients on morbidity and mortality. Kidney Int. 2002; 61: S44-S48.

7. Owen WF, Lew NL, Liu Y, Lowrie EG, Lazarus JM. The Urea Reduction Ratio and Serum Albumin Concentration as Predictors of Mortality in Patients Undergoing Hemodialysis. N Engl J Med. 1993; 329: 1001-1006.

8. Pereira GRM, Strogoff-de-Matos JP, Ruzany F, et al. Early changes in serum albumin: impact on 2-year mortality in incident hemodialysis patients. Brazilian J Nephrol. 2015; 37: 198-205.

9. Rocco M V, Frankenfield DL, Hopson SD, McClellan WM. Relationship between Clinical Performance Measures and Outcomes among Patients Receiving Long-Term Hemodialysis. Ann Intern Med. 2006; 145: 512-519.

10. Malekmakan L, Haghpanah S, Pakfetrat M, et al. Dialysis Adequacy and Kidney Disease Outcomes Quality Initiative Goals Achievement in an Iranian Hemodialysis Population. Iran J Kidney Dis. 2010.

11.

12. Walsh M, Culleton B, Tonelli M, Manns B. A systematic review of the effect of nocturnal hemodialysis on blood pressure, left ventricular hypertrophy, anemia, mineral metabolism, and health-related quality of life. Kidney Int. 2005; 67: 1500-1508.

13. Agarwal R. Hypertension and survival in chronic hemodialysis patients\&\#x2014; Past lessons and future opportunities. Kidney Int. 2005; 67: $1-13$

14. Tentori F, Hunt WC, Rohrscheib M, et al. Which Targets in Clinical Practice Guidelines Are Associated with Improved Survival in a Large Dialysis Organization? J Am Soc Nephrol. 2007; 18: 2377-2384.

15. Méndez-Durán A, Méndez-Bueno JF, Tapia-Yáñez T, Muñoz Montes A, Aguilar-Sánchez L. Epidemiología de la insuficiencia renal crónica en México. Diálisis y Traspl. 2010; 31: 7-11.

16. Garcia-Garcia G, Monteon-Ramos JF, Garcia-Bejarano H, et al. Renal replacement therapy among disadvantaged populations in Mexico: A report from the Jalisco Dialysis and Transplant Registry (REDTJAL). Kidney Int. 2005; 68: S58-S61.

17. Amato D, Alvarez-Aguilar C, Castaneda-Limones R, et al. Prevalence of chronic kidney disease in an urban Mexican population. Kidney Int. 2005; 
68: S11-S17.

18. Lopez Cervantes M. Enfermedad renal crónica y su atención mediante el tratamiento sustitutivo en México. Univ Aut Mex. 2001; 1.

19. Culleton BF. Introduction. J Am Soc Nephrol. 2006; 17: S1-S3.

20. Brimble KS, Rabbat CG, McKenna P, Lambert K, Carlisle EJ. Protocolized Anemia Management with Erythropoietin in Hemodialysis Patients: A Randomized Controlled Trial. J Am Soc Nephrol. 2003; 14: 2654-2661.

21. Depner T, Beck G, Daugirdas J, Kusek J, Eknoyan G. Lessons from the Hemodialysis (HEMO) Study: An improved measure of the actual hemodialysis dose. Am J Kidney Dis. 1999; 33: 142-149.

22. Jindal K, Chan CT, Deziel C, et al. CHAPTER 4: Vascular Access. J Am Soc Nephrol. 2006; 17: S16-S23.
23. Espinach-Roel M, Avellan-Boza M. Indicadores de Calidad en la Unidad de Hemodiálisis del Hospital Rafael Ángel Calderón Guardia. Rev Clínica la Esc Med UCR - HSJD. 2013; 3: 21-29.

24. Salonen T, Reina $T$, Oksa $H$, Sintonen H, Pasternack A. Cost analysis of renal replacement therapies in Finland. Am J Kidney Dis. 2003; 42: 1228 1238.

25. Benain J-P, Faller B, Briat C, et al. Coût de la prise en charge de la dialyse en France. Néphrologie \& Thérapeutique. 2007; 3: 96-106.

26. Al-Saran K, Sabry A. The cost of hemodialysis in a large hemodialysis center Saudi J Kidney Dis Transpl. 2012; 23: 78-82. 